\title{
O COMÉRCIO DE ANIMAIS SILVESTRES e as doenças virais emergentes
}

\section{Wildlife trade and emerging viral diseases}

\author{
Jorge Alberto Manso Raimundo da Rocha ${ }^{1+\mathbb{D}}$; Ana Maria de Mendonca Santos ${ }^{2}$; Elaine Knupp \\ De Brito² ; Brenda Hellen dos Santos Viana²; Etjo Rodrigo Santana Nunes²; Gabriella do Carmo Santos² ; \\ Olga Anais Oliveira Varjão²; Vitoria Lorena De Matos Santana²; Wanessa Victor Barbosa Modesto² \\ *Autor Correspondente: Jorge Alberto Manso Raimundo da Rocha, Universidade Federal de \\ Sergipe (UFS), Av. Desembargador João Bosco de Andrade Lima, 560, \\ Atalaia, Aracaju, SE. CEP: 49037-130. \\ E-mail: jamrrocha@yahoo.com.br
}

Como citar: ROCHA, J. A. M. R. da et al. O comércio de animais silvestres e as doenças virais emergentes. Revista de Educação Continuada em Medicina Veterinária e Zootecnia do CRMV-SP, São Paulo, v. 19, n. 1, 2021, e38156. DOI: https://doi.org/10.36440/recmvz.v19i1.38156.

Cite as: ROCHA, J. A. M. R. da et al. Wild life trade and emerging viral diseases. Journal of Continuing Education in Veterinary Medicine and Animal Science of CRMV-SP, São Paulo, v. 19, n. 1, 2021, e38156. DOl: https://doi.org/10.36440/recmvz.v19i1.38156.

\section{Resumo}

O comércio de animais silvestres fornece mecanismos de transmissão de doenças em níveis que não apenas causam surtos de doenças humanas, mas também ameaça os rebanhos domésticos, os animais silvestres e a saúde dos ecossistemas, a renda agrária e o comércio internacional. 0 contato direto entre seres humanos e animais silvestres, a mistura de animais silvestres não endêmicos com animais silvestres endêmicos e/ou animais domésticos, e padrões limitados de saúde e segurança são todos os critérios para um hotspot zoonótico encontrado nos mercados de animais silvestres. Este artigo de revisão destaca o papel do comércio de animais silvestres na emergência de doenças infecciosas virais.

Palavras-chave: Doenças infecciosas emergentes. Comércio de animais silvestres. Vírus.

\section{Abstract}

The wild animal trade provides mechanisms of disease transmission at levels that not only cause outbreaks of human disease, but also threatens domestic livestock, wild animals and the health of ecosystems, agrarian income and international trade. Direct contact between humans and wild animals, the mixture of non-endemic wild animals with endemic wild animals and/or domestic animals, and limited health and safety standards are all criteria for a zoonotic hotspot found in the wild animal markets. This review article highlights the role of the wild animal trade in the emergence of viral infectious diseases.

Keywords: Emerging infectious diseases. Trade in wild animals. Viral infectious diseases.

1 Docente do Departamento de Fisiologia, Universidade Federal de Sergipe (UFS), Aracaju, SE, Brasil

2 Discente em Medicina Veterinária, Universidade Federal de Sergipe (UFS), Aracaju, SE, Brasil 


\section{Introdução}

Melhorias do saneamento e o desenvolvimento de vacinas e de medicamentos antimicrobianos eficazes diminuíram substancialmente o fardo das doenças infecciosas humanas no mundo desenvolvido em relação aos níveis históricos, mas a emergência de uma série de novas doenças nas décadas de 1970 e 1980, culminando na disseminação global do HIV/AIDS, no entanto, trouxe as doenças infecciosas de volta às agendas políticas. A preocupação pública com as doenças infecciosas emergentes (Emerging Infectious Diseases, EIDs) tem aumentado devido à percepção de que as doenças infecciosas, que anteriormente estavam sob controle, têm disseminação rápida, por exemplo, a síndrome respiratória aguda grave (Severe Acute Respiratory Syndrome, SARS), e que elas geralmente apresentam altas taxas de mortalidade (por exemplo, doença do vírus Ebola), e que o desenvolvimento de medicamentos e vacinas para combatê-las tem sido lento e caro (CUNNINGHAM et al., 2017).

A maioria das doenças infecciosas emergentes tem origem nos animais silvestres, entre elas Lassa, Monkeypox, Marburg, Nipah, SARS e a Síndrome Respiratória do Oriente Médio (Middle East Respiratory Syndrome, MERS), e inúmeras outras doenças virais, tais como o HIV, que veio de primatas não humanos, o Ebola, que veio de morcegos e as estirpes de influenza H5N1 e H1N1, que vieram de pássaros e porcos, respectivamente (WATSA et al., 2020). A doença pandêmica Covid-19, causada pelo coronavírus SARS-CoV-2, é a mais recente EID que aflige a humanidade e as evidências genéticas sugerem que os morcegos são a fonte original de todos os Alfa e Betacoronavírus, incluindo o SARSCoV-2 (BANERJEE et al., 2021).

As doenças zoonóticas endêmicas provocam um ônus recorrente à saúde e aos meios de subsistência das pessoas em todo o mundo, mas sobrecarregam desproporcionalmente os países de baixa e média renda. Os custos das doenças zoonóticas não se restringem às despesas de tratamento humano ou animal e aos esforços de controle. Os distúrbios no comércio e na sociedade causados por surtos de doenças podem ser responsáveis por uma grande parte dos seus custos econômicos (KARESH et al., 2012). A pandemia da Covid-19 tem provocado perda de empregos, insegurança econômica e retração de 4,2\% no PIB mundial (OECD, 2020).

As doenças que são compartilhadas entre as espécies também representam uma carga potencial para todo o ecossistema, afetando a biodiversidade, alterando o comportamento ou a composição das populações de animais e até mesmo relegando as espécies à beira da extinção (WIETHOELTERA et al., 2015). Por exemplo, primatas da Mata Atlântica brasileira, já ameaçados de extinção, como o Alouatta caraya e o Sapajus robustus (conhecidos, respectivamente, como bugio e macaco-prego-de-crista), foram seriamente afetados pela epizootia de febre amarela recente (ICMBIO, 2017).

Desde a década de 1940, houve um aumento consistente no número de eventos de EIDs decorrentes de zoonoses relacionadas aos animais silvestres. A atividade humana é o principal fator desse aumento, com a perda de biodiversidade como um dos principais mecanismos. À medida que as espécies caminham para a extinção, os vírus que sobrevivem nessas espécies estão sob crescente pressão evolutiva para se adaptar e trocar de hospedeiro. Por fim, um número crescente de espécies de vírus desenvolve o potencial de infectar os seres humanos, aumentando assim o risco de EIDs (KHETAN, 2020).

A globalização resultou em um aumento sem precedentes no comércio de produtos de origem animal. Por sua vez, isso impulsionou a criação de novas vias, legais e ilegais, para o fornecimento de organismos silvestres vivos e seus produtos, na forma de animais de companhia, troféus, artesanatos, carne de caça e medicamentos tradicionais (TRAVIS; WATSON; TAUER, 2011). 


\section{Origem das EIDs nos animais silvestres}

Dada a rica biodiversidade animal em nosso planeta, não é de surpreender que os animais silvestres sejam a fonte da maioria das doenças infecciosas humanas, com séculos de contatos íntimos com espécies domesticadas, facilitando a transmissão precoce dos patógenos mais adaptáveis aos seres humanos. 0 reconhecimento recente de que a maioria dos eventos de emergencia de doenças infecciosas tem origem nos animais silvestres destaca a necessidade de um entendimento profundo dos tipos de contatos entre animais silvestres e pessoas, que permitem a transmissão de doenças (JOHNSON et al., 2015).

0 papel dos animais silvestres na emergência das doenças infecciosas tem aumentado significativamente ao longo do tempo. Em média, uma nova doença infecciosa surge em humanos a cada quatro meses. Enquanto muitas são originárias dos animais silvestres, os animais domésticos geralmente servem como uma ponte epidemiológica entre os animais silvestres e os humanos. Esse é especialmente o caso dos animais criados intensivamente, que carecem da diversidade genética que fornece resiliência às doenças infecciosas (UNEP, 2016).

A exploração sem controles da fauna silvestre - seja para sustento ou lucro, legal ou ilegal - coloca os seres humanos em contato direto com inúmeras espécies desconhecidas. 0 aumento do contato ocorre no preparo e consumo de carne de caça e em criadouros de animais silvestres, que geralmente fornecem animais silvestres de forma insustentável e ilegal para consumo ou comércio (WATSA et al., 2020).

Os animais silvestres importados, capturados da natureza ou reproduzidos em criadouros, são encaminhados aos mercados de animais silvestres, onde os animais são sujeitos a condições debilitantes e têm as suas defesas imunológicas enfraquecidas, facilitando a transmissão de doenças: gaiolas superlotadas, biossegurança precária, e derramamento não higiênico de excrementos. 0 contato direto entre seres humanos e animais silvestres, a mistura de espécimens de animais silvestres não endêmicas com animais silvestres endêmicos e/ou animais domésticos, e padrões limitados de saúde e segurança são todos os critérios para um hotspot zoonótico encontrado nos mercados de animais silvestres. Muitos mercados de animais silvestres no mundo atendem a esses critérios e em grande parte, carecem de uma estrutura de vigilância sanitária (WATSA et al., 2020).

Como para muitas zoonoses, os patógenos geralmente causam doenças leves ou subclínicas nos hospedeiros reservatórios e, como os sistemas de vigilância de animais silvestres e animais domésticos não são universalmente adequados para a detecção de doenças clínicas ou presença de patógenos, os seres humanos geralmente agem como populações sentinelas de zoonoses (KARESH et al., 2012).

\section{Vírus de RNA}

Embora os vírus representem apenas uma fração dos aproximadamente 1400 patógenos humanos conhecidos, eles impõem uma carga desproporcional à saúde global. Cerca de $89 \%$ dos 180 vírus de RNA capazes de acometer os seres humanos são zoonóticos, sugerindo que estes vírus têm o potencial de evoluir mais rapidamente que outros tipos de patógenos (MORSE et al., 2012; JOHNSON et al., 2015).

Os vírus de animais silvestres transmitidos nas interfaces de alto risco envolvendo animais silvestres mantidos como animais de estimação, mantidos em santuários ou zoológicos, e vendidos nos mercados de animais silvestres têm alta plasticidade de hospedeiros (ou seja, hospedeiros de várias ordens taxonômicas). Os vírus com alta plasticidade de hospedeiros são os mais propensos à propagação por transmissão secundária de humano para humano e têm uma distribuição geográfica mais ampla (JOHNSON et al., 2015). 
Os vírus transmitidos aos seres humanos durante práticas que facilitam a mistura de diversas espécies animais apresentam plasticidade de hospedeiro elevada. A alta plasticidade viral é uma característica preditiva do potencial pandêmico de vírus, não apenas porque uma ampla gama de hospedeiros são comuns entre os vírus que se espalham de animais para humanos, mas também porque esta característica está associada ao aumento da transmissão de humano para humano. A criação e manutenção de espécies domesticadas taxonomicamente diversas em contato próximo e regular com pessoas, por séculos, permitiu a seleção adaptativa dos vírus de RNA propensos às mutações e capazes de transmissão entre espécies (JOHNSON et al., 2015).

A transmissão de vírus zoonóticos ao homem ocorre por contato direto ou indireto com a fauna silvestre em uma variedade diversificada de interfaces, e esta transmissão (spillover) é mais frequente nas habitações humanas e nos campos agrícolas, bem como nas interfaces durante a exposição ocupacional com animais. Os hospedeiros primatas são fontes de vírus transmitidos por contato direto durante a caça e em laboratórios, enquanto os hospedeiros roedores são mais propensos à transmissão por contato indireto dentro e ao redor de habitações humanas e em campos agrícolas (JOHNSON et al., 2015).

\section{Comércio de animais silvestres}

O comércio global de animais silvestres, abrangendo o fornecimento, a venda e o consumo de espécimes vivos, bem como produtos de animais silvestres, ocorre em uma ampla gama de rotas comerciais, em várias escalas geográficas e econômicas. Ocorre em todas as regiões habitadas por seres humanos e é apoiado por redes complexas que estão aumentando à medida que as populações humanas se expandem (TRAVIS; WATSON; TAUER, 2011).

0 comércio de animais silvestres fornece mecanismos de transmissão de doenças em níveis que não apenas causam surtos de doenças humanas, mas também ameaçam os rebanhos domésticos, os animais silvestres, a saúde dos ecossistemas, o comércio internacional e a renda das populações rurais (UNEP, 2016).

A caça, o transporte, os criadouros de animais silvestres e o comércio de animais silvestres compõem as rotas de transmissão de doenças e seguem de perto o desmatamento e a fragmentação das florestas (DOBSON et al., 2020). É concebível que o comércio de animais silvestres seja o maior fator de risco na disseminação global de doenças infecciosas zoonóticas e emergentes, e é indiscutivelmente um dos principais modos de transmissão (TRAVIS; WATSON; TAUER, 2011).

\section{Prevenção e controle}

Atualmente, poucos países consideram os riscos de doenças como um fator na regulação das importações e exportações de animais silvestres, e falta um status de doença equivalente à CITES (Convention on International Trade in Endangered Species of Wild Fauna and Flora). A triagem de patógenos também não é necessária nem facilitada antes, durante ou após a translocação de produtos da fauna silvestre, deixando o status de patógeno a ser declarado pelo remetente, que pode não ter a experiência necessária para fazer tais determinações (WATSA et al., 2020).

Apesar de muitas evidências de que as doenças associadas aos animais silvestres apresentem um risco potencial significativo aos seres humanos, aos animais domésticos e aos outros animais silvestres, elas ainda recebem uma baixa prioridade por parte dos órgãos governamentais. A maioria dos países utiliza controles de importação para proteger-se apenas contra doenças dos animais domésticos, de importância de saúde pública ou econômica, como raiva e febre aftosa; doenças restritas aos animais silvestres não são incluídas (CUNNINGHAM et al., 2017; TRAVIS; WATSON; TAUER, 2011; UNEP, 2016). 


\section{Conclusão}

O controle das zoonoses requer estruturas jurídicas e políticas criteriosas, instituições que funcionem bem, detecção rápida e um plano de implementação de intervenções. 0 monitoramento da saúde e a identificação de novos patógenos potencialmente zoonóticos em populações de animais silvestres é uma necessidade crítica (JONES et al., 2008). A proibição do comércio de espécies reservatórias de doenças de alto risco é uma medida necessária para prevenir doenças zoonóticas (UNEP, 2016).

A ligação clara entre o desmatamento e a emergência de vírus sugere que esforços para manter a cobertura florestal intacta teriam um grande retorno, mesmo que o seu único benefício seja reduzir os eventos de emergência de vírus (DOBSON et al., 2020). Devido ao subinvestimento histórico nos setores de saúde dos países em desenvolvimento, é provável que o surgimento de doenças persista (UNEP, 2016; DOBSON et al., 2020).

\section{Referências}

BANERJEE, A. et al. Unraveling the zoonotic origin and transmission of SARS-CoV-2. Trends in

Ecology \& Evolution, v. 36, n. 3, p. 180-184, 2021. DOl: https://doi.org/10.1016/j.tree.2020.12.002. Disponível em: https://www.sciencedirect.com/science/article/pii/s0169534720303487. Acesso em: 12 de maio. 2021.

CUNNINGHAM, A. A.; DASZAK, P.; WOOD, J. L. N. One Health, emerging infectious diseases and wildlife: two decades of progress? Philosophical Transactions of the Royal Society B, v. 372, n. 1725, jul. 2017. DOI: https://doi.org/10.1098/rstb.2016.0167. Disponível em: https://royalsocietypublishing. org/doi/10.1098/rstb.2016.0167. Acesso em: 02 de jan. 2021.

DOBSON, A. P. et al. Ecology and economics for pandemic prevention. Science, v. 369, n. 6502, p. 379-381, jul. 2020. DOl: https://doi.org/10.1126/science.abc3189. Disponível em: https://science. sciencemag.org/content/369/6502/379. Acesso em: 21 de nov. 2020.

ICMBIO. Instituto Chico Mendes de Conservação da Biodiversidade. Febre amarela põe em risco macacos, 2017. Disponível em: https://www.icmbio.gov.br/portal/ultimas-noticias/20-geral/8752febre-amarela-poe-em-risco-macacos. Acesso em: 13 de mai. 2021.

JOHNSON, C. K. et al. Spillover and pandemic properties of zoonotic viruses with high host plasticity. Scientific Reports, v. 5, 2015. DOl: https://doi.org/10.1038/srep14830. Disponível em: https://www. nature.com/articles/srep14830. Acesso em: 05 de jan. 2021.

JONES, K. E.; PATEL, N. G.; LEVY, M. A. et al. Global trends in emerging infectious diseases. Nature, v. 451, p. 990-993, 2008. DOl: https://doi.org/10.1038/nature06536. Disponível em: https://www. nature.com/articles/nature06536. Acesso em: 20 de set. 2020.

KARESH, W. B. et al. Ecology of zoonoses: natural and unnatural histories. The Lancet, v. 380, n. 9857, p. 1936-1945, dec. 2012. DOI: https://doi.org/10.1016/S0140-6736(12)61678-X. Disponível em: https://www.thelancet.com/journals/lancet/article/PIIS0140-6736(12)61678-X/fulltext. Acesso em: 21 de out. 2020.

KHETAN, A. K. COVID-19: why declining biodiversity puts us at greater risk for emerging infectious diseases, and what we can do. Journal of General Internal Medicine, v. 35, p. 2746-2747, 2020. DOI: https://doi.org/10.1007/s11606-020-05977-x. Disponivel em: https://link.springer.com/ article/10.1007/s11606-020-05977-x. Acesso em: 02 de out. 2020. 
MORSE, S. S. et al. Prediction and prevention of the next pandemic zoonosis. The Lancet, v. 380, n. 9857, p. 1956-1965, dec. 2012. DOl: https://doi.org/10.1016/s0140-6736(12)61684-5 Disponível em: https://www.thelancet.com/journals/lancet/article/PIIS0140-6736(12)61684-5/ fulltext. Acesso em: 12 de out. 2020.

OECD. Risks that matter 2020: the long reach of COVID-19. OECD Publishing, Paris, apr. 2021. Disponivel em: https://www.oecd.org/coronavirus/policy-responses/risks-that-matter-2020-thelong-reach-of-covid-19-44932654/. Acesso em: 12 de maio. 2021.

TRAVIS, D. A.; WATSON, R. P.; TAUER, A. The spread of pathogens through trade in wildlife. Revue scientifique et technique, v. 30, n. 1, p. 219-239, 2011. DOl: https://doi.org/10.20506/ rst.30.1.2035.

UNEP. Zoonoses: blurred lines of emergent disease and ecosystem health, 2016.

Disponível em: https://wedocs.unep.org/bitstream/handle/20.500.11822/32060/zoonoses. pdf? sequence=1\&isAllowed=y. Acesso em: 27 de dez. 2020.

WATSA, M. et al. Rigorous wildlife disease surveillance. Science, v. 369, n. 6500, 2020. DOI: https://doi.org/10.1126/science.abc0017. Disponível em: https://science.sciencemag.org/ content/369/6500/145. Acesso em: 13 de out. 2020.

WIETHOELTERA, A. K. et al. Global trends in infectious diseases at the wildlife-livestock interface. PNAS, v. 112, n. 31, july. 2015. DOI: https://doi.org/10.1073/pnas.1422741112. Disponível em: https://www.pnas.org/content/112/31/9662. Acesso em: 14 de out. 2020. 